\title{
Correlation of wind and solar power in high-latitude arctic areas in Northern Norway and Svalbard
}

\author{
Kine Solbakken ${ }^{*}$, Bilal Babar, and Tobias Boström \\ Department of Physics and Technology, UiT The Arctic University of Norway, Mailbox 6050, Langnes, 9037 Troms $\varnothing$, Norway
}

\begin{abstract}
This paper assesses the possibilities for combining wind and solar power in a household-scale hybrid renewable energy system in arctic high-latitude areas in the North of Norway. By combining two complementary renewable energy sources, the efficiency and reliability of the power output can be improved compared to a system utilizing wind or solar power independently. This paper assesses the correlation between wind and solar power on different timescales in four different locations in Northern Norway and Svalbard. For all locations complementary characteristics of wind and solar power are found, however, the strength of the correlation is highly variable for each location and for the different timescales. The best correlation for all places is found on a monthly timescale. HOMER is used to run simulations on hybrid renewable energy systems (HRES) for each location. For three of the four locations the HRES produces more power than what is consumed in the household.
\end{abstract}

\section{Introduction}

Recently there has been an increasing interest for smallscale wind and solar power production, both stand-alone systems and grid-connected systems. Due to their intermittent characteristics, these two sources used independently will not provide a secure and continuous power supply, unless combined with considerable storage capacity. In several studies, it has been reported that the problem of intermittency can be overcome to some extent by combining wind and solar power $[1,2]$. When compared to renewable energy systems utilizing only one intermittent energy source, either wind or solar, hybrid solar and wind energy systems have a higher efficiency and reliability [3]. To achieve this, wind and solar power must be complementary energy sources. For stand-alone systems, it is found that by utilizing complementary energy sources, the size of the required energy storage device is reduced [3].

The characteristics of the wind and solar resources vary with the climate, the latitude and the orography as well as variations on a temporal scale. It is therefore not given that wind and solar irradiation will be complementary, and each location must be investigated independently. Several studies have investigated the temporal correlation of individual renewable energy sources over a larger geographical area [4]. Recent studies have also focused on how different intermittent renewable energy sources complement each other and how the combination of two or several complementary renewable sources result in a smoother total power output than the power output from each of the

\footnotetext{
* e-mail: kine.solbakken@uit.no
}

sources independently [4]. In the study by Widèn [2] on the correlation of large scale dispersed wind and solar power, it is concluded that when it comes to the correlation of wind and solar the spatial dispersion is less important than for the correlation of each of them independently.

This study will therefore investigate the correlation between the solar and wind power in different locations independently, aiming for self-reliant small-scale renewable energy production systems (HRES) for households. In addition, this study also uses the simulation program HOMER to simulate the power production for a hybrid renewable energy system for a household connected to the grid.

The four locations assessed in this study, Troms $\varnothing$ $\left(69.65^{\circ} \mathrm{N}\right)$, Pasvik $\left(69.45^{\circ} \mathrm{N}\right)$, Sortland $\left(68.64^{\circ} \mathrm{N}\right)$ and NyAlesund $\left(78.9^{\circ} \mathrm{N}\right)$, are chosen due to available climate data. Troms $\varnothing$ and Sortland is located on the coast, while Pasvik is located on the inland and is therefore expected to have slightly different climate. Ny-Ålesund is located on the island Spitsbergen and is one of the northern most settlements in the world.

These locations are all situated north of the Arctic Circle and therefore have large variations in the solar resource throughout the year, with polar night in the winter, and midnight sun in the summer. For Ny-Ålesund the polar night lasts from October 24th to February 18th. In addition, mountains to the south reduce the period of direct irradiation further, from March 8th to October 8th [5]. In Troms $\varnothing$ and Pasvik the polar night lasts from November 27th to January 16th, while in Sortland December 3rd to January 9th. Consequently, since the sun is completely absent during a mid-winter period, to be able to be self-sufficient on renewable energy an additional source to the solar power is required. 


\section{Data}

The data for Troms $\varnothing$, Pasvik and Sortland are all collected by Agriculture Meteorological Service (Landbruksmeteorologisk Tjeneste, LMT), Bioforsk ${ }^{1}$, to provide data for weather forecast services as well as research. The wind measurements are done by anenometers at an altitude of two meters above ground. The global irradiation is the sum of the direct and diffuse radiation and is measured by a pyranometer in the wavelength range $285-2800 \mathrm{~nm}$ on a horizontal surface. The instruments used on all of Bioforsk's weather stations are either of the type CM11 or CM3 from Kipp \& Zonen for the global irradiation and anenometers from Vector or Friedrics for the wind measurements ${ }^{1}$. The values are saved as hourly values calculated from the average over $60 \mathrm{~min}$. Also the hourly temperature values are collected and used in this study when the power production of the solar power is calculated in HOMER.

For Troms $\varnothing$, Sortland and Pasvik hourly data from 1997 to 2014 is considered in this study. For Troms $\varnothing$, year 2002, 2006, 2008 and 2010 have been excluded from the study, because of a large number of errors. For the remaining years, the errors, about $0.2 \%$ of the data, have been replaced by zero. For Sortland the years 1997, 2000, 2004, 2007, 2010 and 2011 have been excluded and the remaining years has an error of $0.9 \%$. For Pasvik 1997, 2006 and 2007 has been removed, and the data set has an error of $0.7 \%$.

The solar power, wind speed and temperature data for Ny-Ålesund is collected by the Alfred Wegener Institute, Helmholtz Centre for Polar and Marine Research [6,7]. The data set is spanning over an 18-year period lasting from August 1st 1993 to July 31st 2011. The raw data before 1998 consist of $5 \mathrm{~min}$ data registration, while after 1998 it consists of 1 min data registrations. For simplicity, only data after 1998 is considered. From this period, the years 2000, 2003, 2004 and 2008 is excluded due to missing data. For the remaining years, there are no months missing more than $0.6 \%$ of the data, and these values have been set to equal zero. The global irradiation is measured by a pyranometer and with the same data registration interval as for the wind measurements. For further information of the instrumentation the reader is referred to [8] for the wind data and to [5] for the solar irradiation data.

For all data sets, all negative values have been set to zero.

\section{Methods}

The wind power per square meter is calculated from the hourly average data by the following equation:

$$
P_{W}=\frac{1}{2} \rho v_{h o u r}^{3},
$$

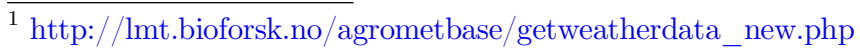

Table 1. Correlation coefficient for hourly, daily and monthly values of wind and solar power.

\begin{tabular}{lrrr}
\hline & Hourly & Daily & Monthly \\
\hline Troms $\varnothing$ & -0.07 & -0.26 & -0.54 \\
Pasvik & +0.12 & -0.07 & -0.23 \\
Sortland & 0.00 & -0.13 & -0.26 \\
NYA & -0.08 & -0.20 & -0.37 \\
\hline
\end{tabular}

where $\rho=1.246 \mathrm{~kg} / \mathrm{m}^{3}$ is the air density at temperature $10{ }^{\circ} \mathrm{C}$ and $v$ is the measured wind speed at $2 \mathrm{~m}$ above ground. Together the wind and the solar power form two data sets referred to as $x$ and $y$ in the equation (2) given below.

To investigate the relationship between the wind power and the solar power at each location the Pearson's correlation coefficient is calculated from the following equation:

$$
r=\frac{\sum_{i=1}^{n}\left(x_{i}-\bar{x}\right)\left(y_{i}-\bar{y}\right)}{\sqrt{\sum_{i=1}^{n}\left(x_{i}-\bar{x}\right)} \sqrt{\sum_{i=1}^{n}\left(y_{i}-\bar{y}\right)}},
$$

where $\bar{x}=\frac{1}{n} \sum_{i=1}^{n} x_{i}$ and $\bar{y}=\frac{1}{n} \sum_{i=1}^{n} y_{i}$, given two datasets $X=x_{1}, x_{2}, \ldots x_{n}$ and $Y=y_{1}, y_{2}, \ldots y_{n}$.

The Pearson correlation coefficient is the simplest and most commonly used method to detect linear relationships between two data sets and indicates by its magnitude the strength of the dependence. If $r=1$ the two data sets correlate perfectly, if $r=-1$ there is a perfect anti correlation, and when $r=0$ there is no linear relationship.

\section{Results}

For all four locations the hourly, daily and monthly wind and solar power available at each site is calculated from the meteorological data. The daily and monthly values are found by calculating the sum of the hourly values. These values are used to calculate the Pearson correlation coefficient given in equation (2) to investigate the relationship between wind and solar power on the three different timescales. The months with polar nights are excluded from the calculation. The results are presented in Table 1.

Common for the four study cases is a weak correlation coefficient for hourly values. The correlation coefficient is so weak that no conclusion can be drawn about the relationship of the wind and solar power on an hourly timescale. When the integration time increases to days, the correlation of the daily wind and solar power becomes negative and the magnitude increases. The best result, with respect to hybrid solar and wind power systems is achieved for monthly values. The same trend, where the magnitude of the correlation coefficient increases as the integration time increases, is also found in the study of wind and solar power by [2].

In addition, it can be seen from Table 1 that the negative correlation is stronger for Troms $\varnothing$ and Ny-Ålesund than Sortland and Pasvik. This indicates that local weather effects affect the characteristics of the wind and solar power resources. 
Table 2. Correlation coefficient for hourly and daily wind and solar energy for each month. The months with polar night are not considered to be applicable.

\begin{tabular}{|c|c|c|c|c|c|c|c|c|}
\hline & \multicolumn{2}{|c|}{ Troms $\varnothing$} & \multicolumn{2}{|c|}{ Pasvik } & \multicolumn{2}{|c|}{ Sortland } & \multicolumn{2}{|l|}{ NYA } \\
\hline & Hour & Day & Hour & Day & Hour & Day & Hour & Day \\
\hline January & $\mathrm{N} / \mathrm{A}$ & $\mathrm{N} / \mathrm{A}$ & $\mathrm{N} / \mathrm{A}$ & $\mathrm{N} / \mathrm{A}$ & $\mathrm{N} / \mathrm{A}$ & $\mathrm{N} / \mathrm{A}$ & $\mathrm{N} / \mathrm{A}$ & $\mathrm{N} / \mathrm{A}$ \\
\hline February & -0.05 & -0.18 & 0.02 & 0.03 & -0.02 & -0.18 & $\mathrm{~N} / \mathrm{A}$ & $\mathrm{N} / \mathrm{A}$ \\
\hline March & -0.04 & -0.27 & 0.06 & -0.10 & -0.02 & -0.16 & -0.05 & -0.17 \\
\hline April & -0.01 & -0.29 & 0.23 & -0.05 & -0.01 & -0.31 & -0.09 & -0.31 \\
\hline May & 0.03 & -0.23 & 0.30 & 0.07 & 0.12 & -0.10 & -0.04 & -0.07 \\
\hline June & 0.11 & -0.01 & 0.25 & -0.07 & 0.20 & 0.07 & 0.04 & 0.00 \\
\hline July & 0.12 & 0.00 & 0.25 & 0.01 & 0.06 & -0.17 & 0.09 & 0.12 \\
\hline August & 0.10 & -0.08 & 0.23 & 0.01 & 0.09 & -0.08 & 0.08 & 0.11 \\
\hline September & -0.02 & -0.25 & 0.21 & -0.06 & 0.00 & -0.24 & -0.11 & -0.27 \\
\hline October & -0.08 & -0.32 & 0.06 & -0.02 & -0.04 & -0.18 & $\mathrm{~N} / \mathrm{A}$ & $\mathrm{N} / \mathrm{A}$ \\
\hline November & $\mathrm{N} / \mathrm{A}$ & $\mathrm{N} / \mathrm{A}$ & $\mathrm{N} / \mathrm{A}$ & $\mathrm{N} / \mathrm{A}$ & -0.05 & -0.10 & $\mathrm{~N} / \mathrm{A}$ & $\mathrm{N} / \mathrm{A}$ \\
\hline December & $\mathrm{N} / \mathrm{A}$ & $\mathrm{N} / \mathrm{A}$ & $\mathrm{N} / \mathrm{A}$ & $\mathrm{N} / \mathrm{A}$ & $\mathrm{N} / \mathrm{A}$ & $\mathrm{N} / \mathrm{A}$ & $\mathrm{N} / \mathrm{A}$ & $\mathrm{N} / \mathrm{A}$ \\
\hline
\end{tabular}

To investigate the relationship between wind and solar power further, the correlation coefficients are calculated from the hourly and daily values for each month separately for each location. This has also been done in the study by Widèn [2]. The results are presented in Table 2. For the hourly values, for all places, except Pasvik, the correlation coefficient varies between weakly positive and weakly negative values. For Pasvik, different from the three other locations, the correlation coefficient is positive and the magnitude indicates that there exists a positive correlation between wind and solar power. A positive correlation between wind and solar power will result in increased fluctuation in the total power production from a HRES based on these two renewable sources.

For the daily correlation coefficients, the trend is similar to Table 1, where the complementary characteristics become more evident when the integration time is increased. For the months where the hourly correlation coefficient is negative, the daily correlation coefficient gets a higher negative value. For those months with a positive hourly correlation coefficient, the daily correlation coefficient is either weakly negative or weakly positive. This is found for all locations. It can also be noticed that the correlation coefficient is weak and even positive during the summer months, June and July for Troms $\varnothing$ and Sortland, and June, July and August for Ny-Ålesund. These months are also the months with the most hours of sun per day. Pasvik, with only positive hourly correlation coefficients, has either weak positive or weak negative daily correlation coefficients for all months. There is therefore no evident linear relationship between the wind and solar power in Pasvik.

For all timescales, Troms $\varnothing$ has stronger negative correlation coefficients than the other three locations. The complementary characteristic is for all locations stronger in the spring and in the fall.

For all study locations, similar hybrid renewable energy systems (HRES) are considered and the simulations are done using HOMER. For all locations the simulations are done with hourly data from 2001 due to low share of missing data and errors for all locations. The HRES consists of a flat plate photovoltaic (PV) system with a rated capacity of $5 \mathrm{~kW}$ and a $6 \mathrm{~kW}$ wind turbine at the rated wind speed $12 \mathrm{~m} / \mathrm{s}$ installed $20 \mathrm{~m}$ above ground. For Troms $\varnothing$, Sortland and Pasvik the PV system is set to have an angle of $45^{\circ}$, while for $\mathrm{Ny}-\mathrm{A}$ lesund the angle is set to be $50^{\circ}$. The PV panels have an efficiency of $20 \%$ with a temperature coefficient of -0.5 and a nominal operating cell temperature of $47^{\circ} \mathrm{C}$.

The energy required for heating has been excluded from the study, and therefore the power demand is not changing throughout the year. The total power demand is set to $5205 \mathrm{kWh} /$ year with a daily demand of $14.26 \mathrm{kWh}$. It is assumed that all locations have grid connection. This means that when the system produces more energy than what is consumed, the excess power is delivered to the grid. When power production is low, electricity is purchased form the grid to be able to meet the demand. Table 3 presents the results from HOMER.

The power input consists of power from the photovoltaic system, the wind turbine and the power purchased from the grid. The power output is the power consumed in the household as well as the power sold from the house to the grid. The total share of the hybrid renewable energy system of the total power output is also given as a percentage in Table 3.

The hybrid solar and wind power is able to deliver a considerable share of the household electricity demand. The best result is achieved for Troms $\varnothing$ and Ny-Alesund where the system contributes with $85 \%$ of the total power input. Also a large share of the power produced is sold to the grid. For Sortland and Pasvik the power production is lower, but still contributes with a considerable share of the total power input to the household.

The large difference in power produced by the HRES in the four locations is mainly due to the wind power production. The wind power production contributes with $56 \%$ and $65 \%$ in Troms $\varnothing$ and Ny-Ålesund respectively. In Sortland and Pasvik on the other hand, the wind power 
Table 3. The performance of the HRES based on meteorological data from 2001. Values are given in $\mathrm{kWh}$ and percentage share of each source in the system. PV, wind and purchases from the grid are the power input. The power delivered by the HRES is also given as a percentage share of the total power input. The load and sales are the consumption and the energy given back to the grid.

\begin{tabular}{|c|c|c|c|c|c|c|c|c|c|c|c|}
\hline & \multicolumn{2}{|l|}{ PV } & \multicolumn{2}{|c|}{ Wind } & \multicolumn{2}{|c|}{ Purchase } & \multirow{2}{*}{$\begin{array}{l}\text { HRES } \\
\%\end{array}$} & \multicolumn{2}{|l|}{ Load } & \multicolumn{2}{|l|}{ Sale } \\
\hline & $\mathrm{kWh}$ & $\%$ & $\mathrm{kWh}$ & $\%$ & $\mathrm{kWh}$ & $\%$ & & $\mathrm{kWh}$ & $\%$ & $\mathrm{kWh}$ & $\%$ \\
\hline Troms $\varnothing$ & 3678 & $29 \%$ & 7024 & $56 \%$ & 1909 & $15 \%$ & $85 \%$ & 5205 & $42 \%$ & 7258 & $58 \%$ \\
\hline NYA & 3066 & $22 \%$ & 9061 & $65 \%$ & 1890 & $13 \%$ & $86 \%$ & 5205 & $38 \%$ & 8688 & $62 \%$ \\
\hline Pasvik & 3704 & $48 \%$ & 916 & $12 \%$ & 3125 & $40 \%$ & $59 \%$ & 5205 & $69 \%$ & 2392 & $31 \%$ \\
\hline Sortland & 3799 & $46 \%$ & 1682 & $20 \%$ & 2865 & $34 \%$ & $65 \%$ & 5205 & $64 \%$ & 2989 & $36 \%$ \\
\hline
\end{tabular}

production is low. The solar power production is similar for all locations, except for slightly lower production in $\mathrm{Ny}-$ Alesund. Based on the data available from the weather stations in these two locations, it is probably more economical with a system consisting of only solar power. However, before any conclusions are drawn, the locations of the wind measurements should be investigated further. It is important to emphasize that these measurements are carried out to gain knowledge about weather and climate. The locations of these weather stations might not be optimal for power production. Especially in Sortland, which is located on the coast, similar to Troms $\varnothing$, the wind can be expected to be stronger than what the data indicates.

For all locations, except Pasvik, the power produced by the HRES exceeds the power consumed by the household. This result suggests that the components of the HRES, especially the wind turbine, are oversized.

\section{Discussion and conclusion}

In this study, the correlation between the wind and solar power resources has been investigated for four different locations in high-latitude arctic areas in the North of Norway and Svalbard. For three of the four locations the correlation coefficients of wind and solar power are negative and therefore indicate that there exists a complementary characteristic, though weak, between the two sources. The negative correlation is positive for the feasibility of hybrid wind and solar energy systems. To assess if there exists a correlation between wind and solar energy resources that is beneficial for hybrid renewable energy systems, a further study should include a larger number of locations. Future study should also investigate how strong the negative correlation is needed to smoothen the power output. The temperature effect for both solar power and wind power should also be included. Colder temperature increases the efficiency of the solar cells. In addition, colder air means higher air density and will therefore increase the wind power during the winter months.
HOMER is used to simulate the power production in each location for a grid-connected hybrid solar and wind energy system. For three of the four locations the total power produced by the HRES exceeds the power demand of the household. For all locations, the solar power production is high, but only two of the locations are found suitable for wind production. A future study should also include energy storage to balance energy flow better.

\section{References}

1. S.A. Dos Anjos, A.S.A. da Silva, B. Stošić, T. Stošić, Long term correlations and cross-correlations in wind speed and solar radiation temporal series from Fernando de Noronha Island, Brazil, Physic. A 424, 90 (2015)

2. J. Widèn, Correlation between large-scale solar and wind power in a future scenario for Sweden, IEEE Trans. Sustain. Energy 2, 177 (2011)

3. W. Zhou, C. Lou, Z. Li, L. Lu, H. Yang, Current status of research on optimum sizing of stand-alone hybrid solar-wind power generation systems, Appl. Energy 87, 380 (2010)

4. J. Widèn, N. Carpman, V. Castellucci, D. Lingfors, J. Olauson, F. Remouit, M. Bergkvist, M. Grabbe, R. Waters, Variability assessment and forecasting of renewables: a review for solar, wind, wave and tidal resources, Renew. Sustain. Energy Rev. 44, 356 (2015)

5. M. Maturilli, A. Herber, G. König-Langlo, Surface radiation climatology for $\mathrm{Ny}$-Ålesund, Svalbard $\left(78.9^{\circ} \mathrm{N}\right)$, basic observations for trend detection, Theor. Appl. Climatol. 120, 331 (2015)

6. M. Maturilli et al., Basic measurements and other of radiation from the Baseline Surface Radiation Network (BSRN) Station Ny-Ålesund in the years 1992-2013, reference list of 253 datasets (2014). DOI:10.1594/PANGAEA.150000

7. M. Maturilli et al., Continuous meterological observations at station Ny-Ålesund 1993-08 to 2011-07 (2013). DOI:10.1594/ PANGAEA.793046

8. M. Maturilli, A. Herber, G. König-Langlo, Climatology and time series of surface meteorology in Ny-Ålesund, Svalbard, Earth Syst. Sci. Data 5, 155 (2013) 